\title{
RESEARCH
}

\section{EVALUATION OF THE FACTORS PROLONGING THE DISCHARGE HOME OF PATIENTS IN A PALLIATIVE CARE CENTER}

Turkish Journal of Geriatrics

DOI: 10.31086/tigeri.2021.231

2021; 24(3): 342-350

- Gülten UTEBEY ${ }^{1}$

- Julide ERGIL ${ }^{1}$

CORRESPONDANCE

\section{${ }^{1}$ Gülten UTEBEY}

University of Health Sciences Diskapi

Yildirim Beyazit Training and Research

Hospital, Department of Anesthesiology and

Reanimation, Ankara, Turkey

Phone: +905327818811

e-mail: gultenutebey@yahoo.com.tr

Received: Aug 17, 2021

Accepted: Aug 30, 2021

${ }^{1}$ University of Health Sciences Diskapi Yildirim Beyazit Training and Research Hospital, Department of Anesthesiology and Reanimation, Ankara, Turkey

\section{Abstract}

Introduction: The need for palliative care increases with advanced age and chronic diseases. We evaluated the factors that prolong discharge from palliative care center to improve the efficient use of existing palliative care beds.

Materials and Methods: This retrospective study included patients discharged from a palliative care center. The demographic and clinical features of the two groups, differentiated by length of stay, were compared.

Results: This study included 103 patients Group 1, $n=56$, aged $67.7 \pm 16.4$ years and Group 2, n = 47, aged $67.6 \pm 14.1$ years. The length of stay in the center was $12.4 \pm 4.8$ days for Group 1 and $42.4 \pm 15.8$ days for Group 2. The number of patients with heart failure was higher in Group 2 than in Group 1 $(p=0.006)$, and the number of patients receiving oral nutrition was higher in Group $1(p=0.031)$. The gastrostomy status of Group 2 was higher than that of Group 1 ( $p=0.035$ ). Grades 1 and 3-4 decubitus ulcers were more common in Group 1 than in Group $2(p=0.009)$, and the lowest sodium levels were lower in Group $1(p=0.033)$.

Conclusion: Anoxic brain injury as a referral diagnosis, presence of heart failure, and lower serum sodium levels were associated with a longer length of stay in palliative care center. It is important to determine the factors affecting long-term hospitalization and discharge so that more patients can benefit from inpatient palliative care services.

Keywords: Palliative Care; Length of Stay; Patient Discharge. 


\section{INTRODUCTION}

Palliative care $(P C)$ is defined as an approach that improves the quality of life of patients and their families when facing life-threatening diseases (1). The need for PC is growing due to the increases in the elderly population and the prevalence of chronic life-threatening diseases (2). Determining the factors affecting the discharge of patients treated in a palliative care center ( $\mathrm{PCC}$ ) may contribute to the efficient use of existing PCC beds (3). The aim of this study was to evaluate the factors that prolong patients' discharge from a PCC.

\section{MATERIALS AND METHODS}

\section{Ethical approval and study protocol}

This study was approved by the Instutional Ethical Committee of our university- affiliated training and research hospital in Ankara, Turkey (December 28, 2020, number 101/08, Chairperson: Professor GS; Clinicaltrials.gov identifier: NCT04755374). Written informed consent was obtained from all patients or their relatives. All procedures were performed in accordance with the principles of the Declaration of Helsinki.

The records of patients referred to our university-affiliated training and research hospital's PCC between August 2018 and September 2020 and those who were discharged were evaluated retrospectively. Patients were excluded if their records were incomplete, they refused to participate in the study, they were transferred to intensive care, or they died.

\section{Data sources}

The data were obtained from the hospital computerized database. The following data were recorded: age, gender, body mass index, length of stay (LOS) in the PCC, diagnosis (cancer, cerebrovascular disease, Alzheimer's disease/dementia, motor neurone disease, Parkinson's disease, chronic obstructive pulmonary disease [COPD], trauma, infec- tion), a comorbid disease (hypertension, diabetes mellitus, heart failure, chronic kidney disease, epilepsy), performance assessed on the Karnofsky performance scale (KPS), clinical features (spontaneous breathing, tracheostomy, invasive home mechanical ventilation, oral nutrition, parenteral nutrition, gastrostomy, decubitus ulcers, mobilization), education status of the patient and their caregiver, lowest and highest hemoglobin values, serum sodium ( $\mathrm{Na}$ ) levels, and white blood cell counts. The KPS measures a patient's health status based on their self-care capacity, ability to carry out daily tasks, and general functioning for survival. The KPS comprises 11 classes, which progress from 0 (death) to 100 points (normal condition without any disease) (4). The patients discharged home were grouped according to their LOS in the PCC as Group 1 (discharged in less than or equal to 21 days) or Group 2 (discharged after more than 21 days) and analyzed accordingly (5).

\section{Data analysis}

Statistical analyzes were performed using IBM SPSS for Windows Version 22.0 package program. Numerical variables are mean \pm standard deviation or median [25-75. percentile] values and categorical variables were summarized with numbers and percentages. Parametric test assumptions (normality and homogeneity of variances) were checked before comparing the groups in terms of numerical variables. Whether the numerical variables showed normal distribution was examined by Shapiro Wilks test. The homogeneity of the variances of the compared groups was examined using the Levene test. The difference between the two independent groups in terms of numerical variables was examined using the $t$ test in the independent groups if the parametric test conditions were met and with the Mann Whitney $U$ test if they were not. Comparison of more than two groups in terms of numerical variables was made with the Kruskal Wallis test. Whether there was a difference between the groups in terms of categorical variables was examined us- 
ing the chi-square test or Fisher's exact test. The relationship between numerical variables was given by Spearman correlation coefficient. Multiple stepwise linear regression analysis was applied to determine the factors determining the length of hospital stay. A value of $p<0.05$ was accepted as statistically significant.

\section{RESULTS}

During the 2-year study period, 197 patients were admitted to the PCC. Among them, 34 patients died, and 30 patients were transferred to intensive care unit; therefore, they were excluded from the study. Data from 103 patients (Group 1, $\mathrm{n}=56$; Group 2, $n=47$ ) were included in the final analyses (Figure 1). All patients were referred from an intensive care unit. The LOS was $12.4 \pm 4.8$ (4-21) days and $41.4 \pm 15.8$ (22-90) days in Groups 1 and 2 , respectively. The groups were comparable with respect to patient and caregiver characteristics, except for patient body mass index, which was higher in Group 2 (Table 1).
The frequencies of diagnoses and conditions of the patients are listed in Table 2. The number of patients with heart failure was significantly higher in Group 2 than in Group 1 (14 [25.0\%] vs. 25 [53.2\%]; $\mathrm{p}=0.006)$. More patients in Group 1 received oral nutrition (27 [48.2\%]) than in Group 2 (12 [25.5\%], p $=0.031$ ), and the gastrostomy status of Group 2 patients (28 [50.0\%]) was higher than that of Group 1 patients (34 [72.3\%], $p=0.035$ ). Grades 1 and 3-4 decubitus ulcers were observed more frequently in Group 1 than in Group 2 (10 [17.9\%] vs. 8 [17.0\% ] patients and 7 [12.5\%] vs. 2 [4.3\%] patients, respectively; $p=0.009$ ). There were no statistically significant differences in mobilization status $(p=0.057)$ or Karnofsky performance scale scores ( $p=0.254)$ between the groups (Table 2). The lowest recorded $\mathrm{Na}$ level was significantly lower in Group 1 than Group $2(133.8 \pm 4.95 \mathrm{mmol} / \mathrm{L}$ vs $135.8 \pm 4.5 \mathrm{mmol} / \mathrm{L} ; \mathrm{P}=$ 0.033) (Table 3).

Multiple logistic regression was used to model LOS and patient characteristics. Compatibility tests with chi-square and pseudo $\mathrm{R}^{2}$ tests were used to test the compatibility of the model and explain the

Table 1. Comparison of patients characteristics between groups

\begin{tabular}{|c|c|c|c|c|}
\hline & & $\begin{array}{c}\text { Group 1 } \\
\text { Discharged } \\
\leq 21 \text { days }(n=56)\end{array}$ & $\begin{array}{c}\text { Group } 2 \\
\text { Prolonged discharge } \\
>21 \text { days }(n=47)\end{array}$ & $p$ value \\
\hline \multirow[t]{2}{*}{ Gender $^{\mathrm{a}}$} & Female & $26(46.4)$ & $20(42.6)$ & 0.845 \\
\hline & Male & $30(53.6)$ & $27(57.4)$ & \\
\hline Age, (years) ${ }^{b}$ & & $67.7 \pm 16.4$ & $67.6 \pm 14.1$ & 0.971 \\
\hline $\mathrm{BMI}\left(\mathrm{kg} / \mathrm{m}^{2}\right)^{\mathrm{b}}$ & & $25.4 \pm 3.3$ & $26.8 \pm 3.0$ & $0.029^{*}$ \\
\hline \multirow{4}{*}{ Education Status of the Patient, a } & Illiterate & $11(19.6)$ & $8(17.0)$ & \multirow{4}{*}{0.586} \\
\hline & Primary school & $22(39.3)$ & $24(51.1)$ & \\
\hline & High school & $19(33.9)$ & $11(23.4)$ & \\
\hline & University & $4(7.1)$ & $4(8.5)$ & \\
\hline \multirow{4}{*}{ Education Status of the Patient's Care giver, a } & Illiterate & $1(1.8)$ & $3(6,4)$ & \multirow{4}{*}{0.103} \\
\hline & Primary school & $14(25.0)$ & $15(31.9)$ & \\
\hline & High school & $34(60.7)$ & $18(38.3)$ & \\
\hline & University & $7(12.5)$ & $11(23.4)$ & \\
\hline
\end{tabular}

a numbers (percentage), bmean \pm standard deviation, BMI: body mass index

*Statistically significant $p$ values are highlighted. 
Table 2. Comparison of diagnose, co-morbid disease and the clinical features between groups

\begin{tabular}{|c|c|c|c|}
\hline & $\begin{array}{c}\text { Group } 1 \\
\text { Discharged } \\
\leq 21 \text { days } \\
(n=56)\end{array}$ & $\begin{array}{l}\text { Group } 2 \\
\text { Prononged } \\
\text { discharge } \\
>21 \text { days } \\
(n=47)\end{array}$ & $p$ value \\
\hline Cancer, ${ }^{\mathrm{a}}$ & $8(14.3)$ & $6(12.8)$ & 1.000 \\
\hline Cerebrovascular disease, a & $16(28.6)$ & $18(38.3)$ & 0.404 \\
\hline Alzheimer's- Dementia, a & $18(32.1)$ & $10(21.3)$ & 0.311 \\
\hline Anoxic brain injury, a & $3(5.4)$ & $6(12.8)$ & 0.294 \\
\hline Motor neurone disease, a & $1(1.8)$ & $1(2.1)$ & NA \\
\hline Parkinson's disease ${ }^{\text {a }}$ & $4(7.1)$ & $3(6.4)$ & 1.000 \\
\hline COPD, a & $10(17.9)$ & $2(4.3)$ & 0.067 \\
\hline Trauma, a & $7(12.5)$ & $6(12.8)$ & 1.000 \\
\hline Infection, a & $5(8.9)$ & $9(19.1)$ & 0.223 \\
\hline Hypertension, a & $35(62.5)$ & $31(66.0)$ & 0.874 \\
\hline Diabetes mellitus, a & $18(32.1)$ & $17(36.2)$ & 0.825 \\
\hline Heart failure, ${ }^{a}$ & $14(25.0)$ & $25(53.2)$ & $0.006^{*}$ \\
\hline Chronic kidney disease, ${ }^{a}$ & $4(7.1)$ & $5(10.6)$ & 0.729 \\
\hline Epilepsy, a & $13(23.2)$ & $11(23.4)$ & 1.000 \\
\hline $\begin{array}{l}\text { Number of patient having } \\
>1 \text { co-morbidity, a }\end{array}$ & $51(91.1)$ & $43(91.5)$ & 1.000 \\
\hline $\begin{array}{l}\text { Number of patient having } \\
>3 \text { co-morbidity, a }\end{array}$ & $9(16.1)$ & $12(25.5)$ & 0.346 \\
\hline Spontaneous breathing, a & $47(83.9)$ & $32(68.1)$ & 0.097 \\
\hline Spontaneous breathing with tracheostomy, a & $7(12.5)$ & $13(27.7)$ & 0.092 \\
\hline Invasive home mechanical ventilation, a & $3(5.4)$ & $4(8.5)$ & 0.699 \\
\hline Oral nutrition, a & $27(48.2)$ & $12(25.5)$ & $0.031^{*}$ \\
\hline Parenteral nutrition, a & $1(1.8)$ & $1(2.1)$ & NA \\
\hline Gastrostomy present, a & $28(50.0)$ & $34(72.3)$ & $0.035^{*}$ \\
\hline Decubitus ulcers, ${ }^{a}$ & $27(48.2)$ & $32(68.1)$ & 0.067 \\
\hline Grade 1 & $10(17.9)$ & $8(17,0)$ & \multirow{3}{*}{$0.009^{*}$} \\
\hline Grade 2 & $10(17.9)$ & $22(46,8)$ & \\
\hline Grade 3-4 & $7(12.5)$ & $2(4.3)$ & \\
\hline Mobilization & $20(35.7)$ & $8(17.5)$ & 0.057 \\
\hline Karnofsky Performance Status, ${ }^{\text {b }}$ & $45 \pm 8.5$ & $43.6 \pm 7.9$ & 0.254 \\
\hline
\end{tabular}

a numbers (percentage), bmean \pm standard deviation, COPD: chronic obstructive pulmonary disease, KPS: Karnofsky performance scale scores (0 to 100 points)

${ }^{\star}$ Statistically significant $p$ values are highlighted. 
Table 3. Comparison of laboratory variables between groups.

\begin{tabular}{|c|c|c|c|}
\hline & $\begin{array}{c}\text { Group } 1 \\
\text { Discharged in } \\
\leq 21 \text { days } \\
(n=56)\end{array}$ & $\begin{array}{c}\text { Group } 2 \\
\text { Prolonged discharge } \\
>21 \text { days } \\
(n=47)\end{array}$ & $p$ value \\
\hline Lowest hemoglobin (g/dL), a & $10.22 \pm 2.00$ & $10.72 \pm 1.98$ & 0.211 \\
\hline Highest hemoglobin ( $/ / d L)$, a & $11.61 \pm 2.01$ & $12.27 \pm 2.00$ & 0.102 \\
\hline Lowest serum sodium ( $\mathrm{mmol} / \mathrm{L})$ a & $133.82 \pm 4.95$ & $135.87 \pm 4.56$ & $0.033^{x}$ \\
\hline Highest serum sodium ( $\mathrm{mmol} / \mathrm{L})$, a & $141.48 \pm 6.23$ & $142.26 \pm 5.69$ & 0.516 \\
\hline Lowest white blood cell $\left(\times 10^{3} / \mu \mathrm{L}\right)$, a & $7.26 \pm 2.08$ & $7.91 \pm 2.39$ & 0.328 \\
\hline Highest white blood cell $\left(\times 10^{3} / \mu \mathrm{L}\right)$, a & $13.71 \pm 4.94$ & $14.70 \pm 5.24$ & 0.148 \\
\hline
\end{tabular}

a mean \pm standard deviation

*Statistically significant $p$ values are highlighted.

Table 4. Multiple linear regression analysis of the factors affecting length of stay

\begin{tabular}{|l|c|c|c|}
\hline & B (95\% Cl) & Beta & $P$ \\
\hline Heart failure & $11.16(4.37-17.95)$ & 0.29 & 0.002 \\
\hline COPD & $-14.96(-25.24-4.69)$ & -0.26 & 0.005 \\
\hline Lowest recorded sodium level (mmol/L) & $0.93(0.25-1.61)$ & 0.24 & 0.008 \\
\hline Anoxic brain injury & $15.14(3.42-26.86)$ & 0.23 & 0.012 \\
\hline
\end{tabular}

$F=7.69(p<0.001), R^{2}=\% 23.9$

changes in the data. According to the Nagelkerke test result, the independent variables included in the model explained approximately $23.9 \%$ of the changes in LOS, which was the dependent variable. Utilizing a stepwise regression to identify the predictive factors for our regression model, we found that heart failure, the lowest $\mathrm{Na}$ level, and anoxic brain injury were associated with a significantly longer LOS, while a COPD diagnosis was associated with a significantly shorter LOS (Table 4). The analyses showed that a $1-\mathrm{mmol} / \mathrm{L}$ increase in serum $\mathrm{Na}$ levels caused a 0.93-day increase in $\operatorname{LOS}(F=7.69$, $\mathrm{R}^{2}=23.9, \mathrm{p}=0.008$ ).

\section{DISCUSSION}

It is important to determine the factors that affect long-term hospitalization and discharge so that more patients can benefit from inpatient PC services. In this study, we examined the LOS in the PCC at a training and research hospital in Turkey and identified the possible factors related to prolonged hospitalization. The results showed that presence of heart failure, anoxic brain injury as a referral diagnosis, and lower serum $\mathrm{Na}$ levels were associated with a significantly longer LOS, while a COPD diagnosis was associated with a significantly shorter LOS. 
Figure 1. Flowchart of patient enrolment in the study

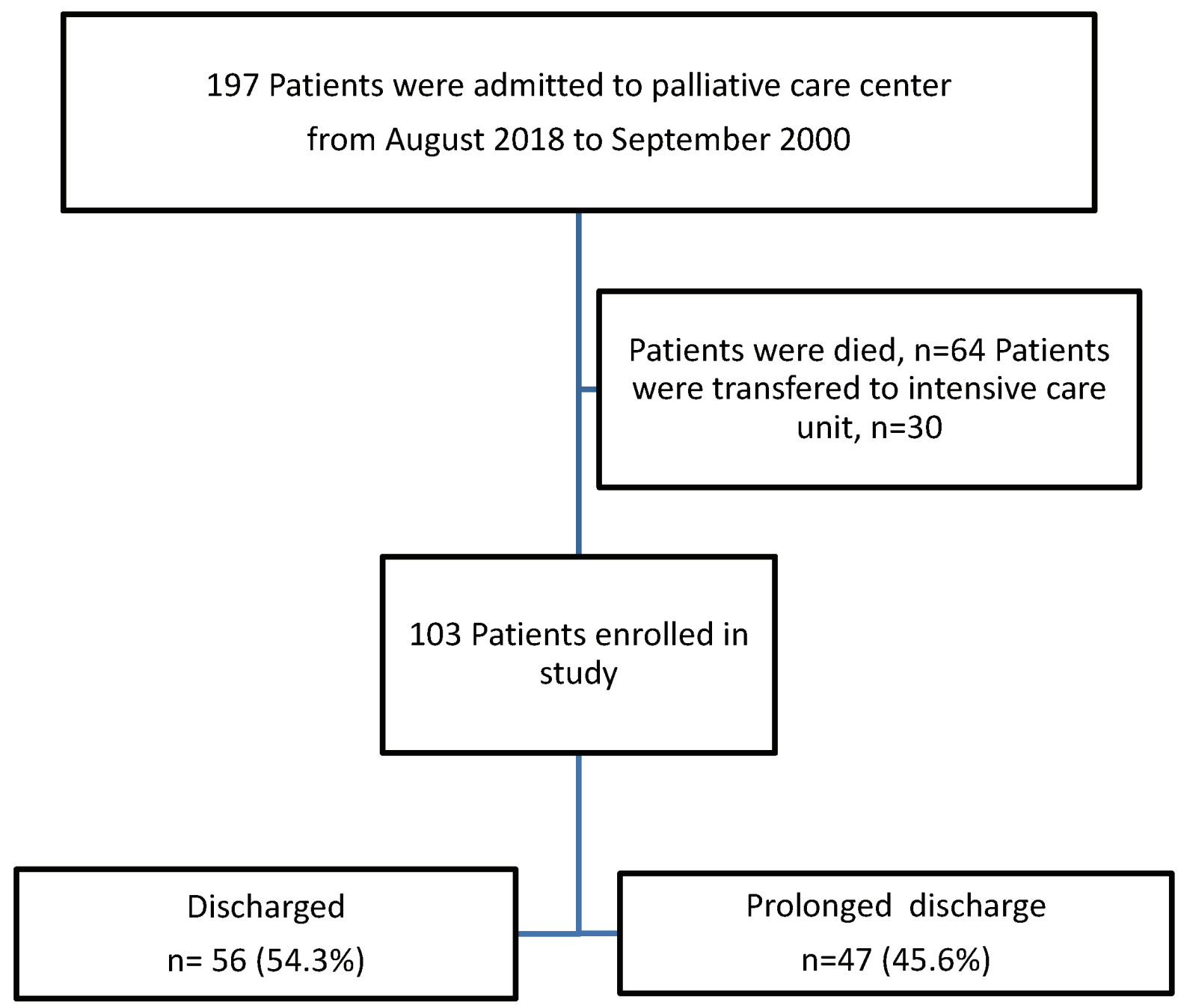

PC is provided for a variety of serious illnesses and conditions for patients across a wide range of ages with the aim of increasing quality of life by providing symptom control and decreasing suffering $(1,6)$. The capacity of PCCs and clinical experience in this field in Turkey is limited (3). Patients can be discharged home from PCCs when they are stable, symptom control is achieved, and family support is sufficient.
The diagnoses and clinical features of patients admitted to PCCs can affect their LOS (3). The patients in the current study had multiple chronic diseases, and the mean KPS scores showed that most of the patients required considerable assistance and were disabled with the need for special care and assistance. The majority of patients were admitted for diagnosis other than cancer. The most prevalent diagnoses were neurological disorders 
followed by COPD, trauma-related conditions, and infections. The most common comorbid diseases were hypertension, diabetes mellitus, heart failure, and epilepsy. We did not document the differences in comorbid diseases between the groups given the number of such diseases, which suggests that it is not the number of comorbid diseases but the severity of the comorbidity that has an impact on LOS.

Anoxic brain injury is a medical condition with devastating consequences caused by prolonged hypoxia (7). In a study investigating the LOS in a PCC of patients with traumatic brain injury, the mean LOS was 34.0 days (8). Notably, the LOS in the PCC was significantly higher among patients with a gastrostomy who were immobile and not fed orally.

Anemia can contribute to the symptoms of PC patients (9). Infection and decubitus ulcers are factors that can affect PCC LOS (3), and urinary tract infections are common in $P C$ patients (10). In a study reporting a mean $27.2 \pm 30.9$ day stay in a PCC, advanced age, cancer, a diagnosis of hypoxic brain injury, the presence of hypertension, gastrostomy, parenteral nutrition, and infectious complications increased the LOS (3). In the patient group in our study, infection, anemia, and decubitus ulcers were not associated with a prolonged time to discharge.

Heart failure is more common with increasing age and is a worldwide public health problem (11). It is a complex clinical syndrome associated with various symptoms, including dyspnea, fatigue, peripheral edema, and depression. Heart failure is one of the factors that affect PCC LOS (12). One study concluded that care pathways for the treatment of heart failure decreased mortality rates and the length of hospital stay, but no differences were observed in the readmission rates and hospitalization costs (13). In our study, patients with heart failure had a longer time to discharge from the PCC.

Hyponatremia is defined as a sodium level < $135 \mathrm{mmol} / \mathrm{L}$ (14). Hyponatremia management can improve the quality of life of patients with PC (15). Symptoms of hyponatremia may include nausea, vomiting, headache, stupor, coma, seizures, fatigue, and cognitive impairment. Hyponatremia may be a contributing factor to the symptoms of $\mathrm{PC}$ patients (16) and is associated with increased mortality, prolonged hospital stay, and increased healthcare costs (17). Comorbid conditions may be the main cause of mortality in patients with severe hyponatremia (18). In a study investigating the incidence of hyponatremia in patients referred for PC, 61.1\% of patients with a malignant disease and $39.9 \%$ of those with a non-malignant disease were found to have hyponatremia (15). In hospitalized cancer patients, hyponatremia may be the reason for long hospital stay (19). A study found a significant association between $\mathrm{Na}$ levels and length of hospitalization; for those discharged to their homes, the LOS was $16 \%-29 \%$ longer when the patients' $\mathrm{Na}$ levels were below $135 \mathrm{mmol} / \mathrm{L}$ (14).

In the present study, the absolute value of the "lowest Na level" in the prolonged discharge group (Group 2) was well within normal ranges; however, the fact that the LOS was higher in the patient group with the higher "lowest Na level" indicated that these patients needed to be hospitalized longer to correct their hyponatremia. Therefore, our interpretation of the results pertaining to the LOS-Na level relationship was that in patients with hyponatremia, a 1-mmol/L improvement in serum $\mathrm{Na}$ levels required a 0.93-day increase in LOS.

PC is difficult for patients with COPD because of its unpredictable disease course (20). In patients with COPD, PC is not limited to the terminal stage and can be provided at an early stage alongside curative care (21).

This study has several limitations. First, it was a retrospective study, and the number of included patients was small. Second, we did not include the patients' serum $\mathrm{Na}$ levels on admission in the analyses; therefore, we could not comment on this issue. Furthermore, patients' medications and simultaneous glucose levels during hyponatremia may have affected our results, but we did not include such 
data in our analyses. Additionally, we did not stratify patients with COPD and heart failure according to disease severity, which may have affected our results.

It is important to determine the factors that affect long-term hospitalization and discharge so that more patients can benefit from inpatient PC services. A better understanding of the factors that may cause prolonged hospitalization in PC units and the ability to cope with these problems may

\section{REFERENCES}

1. Radbruch L, De Lima L, Knaul F, et al. Redefining Palliative Care-A New consensus-based definition. J Pain Symptom Manage 2020;60 (4): 754-764. (PMID: 32387576)

2. Meier DE. Palliative care in hospitals. J Hosp Med 2006;1 (1): 21-8. (PMID: 17219467)

3. Dincer M, Kahveci K, Doger C. An examination of factors affecting the length of stay in a palliative care center. J Palliat Med 2018; 21 (1): 11-15. ( PMID: 28622477)

4. Liem BJ, Holland JM, Kang MY, Hoffelt SC, Marquez CM. Karnofsky performance status assessment: resident versus attending. J Cancer Educ 2002;17 (3): 138-41. (PMID: 12243218)

5. Challis D, Hughes J, Xie C, Jolley D. An examination of factors influencing delayed discharge of older people from hospital. Int J Geriatr Psychiatry 2014;29 (2): 160-8. (PMID: 23661304)

6. Chahine LM, Malik B, Davis M. Palliative care needs of patients with neurologic or neurosurgical conditions. Eur J Neurol 2008;15 (12): 1265-72. (PMID: 19049542)

7. Pollock JM, Whitlow CT, Deibler AR, et al. Anoxic injury-associated cerebral hyperperfusion identified with arterial spin-labeled MR imaging. AJNR Am J Neuroradiol 2008; 29 (7): 1302-7. (PMID: 18451089)

8. Kahveci K, Dinçer M, Doger C, Yaricı AK. Traumatic brain injury and palliative care: a retrospective analysis of 49 patients receiving palliative care during 2013-2016 in Turkey. Neural Regen Res 2017;12 (1): 77-83. (PMID: 28250751) help shorten the length of hospitalization.

In conclusion, we demonstrated that anoxic brain injury as a referral diagnosis, the presence of heart failure, and serum $\mathrm{Na}$ levels were associated with a significantly longer LOS in the PCC, while a COPD diagnosis was associated with a significantly shorter LOS.

Conflict of interest: The authors declare no conflicts of interest.

9. Neoh K, Gray R, Grant-Casey J, et al. National comparative audit of red blood cell transfusion practice in hospices: Recommendations for palliative care practice. Palliat Med 2019;33 (1): 102-108. (PMID: 30260291)

10. Pereira J, Watanabe S, Wolch G. A retrospective review of the frequency of infections and patterns of antibiotic utilization on a palliative care unit. J Pain Symptom Manage. 1998;16 (6): 374-81. (PMID: 9879162)

11. Falk H, Ekman I, Anderson R, Fu M, Granger B. Older patients' experiences of heart failure-an integrative literature review. J Nurs Scholarsh 2013;45 (3): 24755. (PMID: 23617442)

12. Hjelmfors L, Strömberg A, Friedrichsen M, Martensson J, Jaarsma T. Communicating prognosis and end-of-life care to heart failure patients: a survey of heart failure nurses' perspectives. Eur J Cardiovasc Nurs 2014;13 (2): 152-61. (PMID: 24480779)

13. Kul S, Barbieri A, Milan E, Montag I, Vanhaecht K, Panella M. Effects of care pathways on the in-hospital treatment of heart failure: a systematic review. BMC Cardiovasc Disord 2012;25;12: 81. (PMID: 23009030)

14. Al Mawed S, Pankratz VS, Chong K, Sandoval M, Roumelioti ME, Unruh M. Low serum sodium levels at hospital admission: Outcomes among 2.3 million hospitalized patients. PLoS One 2018;22;13(3):e0194379. (PMID: 29566068)

15. Nair S, Mary TR, Tarey SD, Daniel SP, Austine J. Prevalence of Hyponatremia in Palliative Care Patients. Indian J Palliat Care 2016;22 (1): 33-7. (PMID: 26962278) 
16. Filippatos TD, Makri A, Elisaf MS, Liamis G. Hyponatremia in the elderly: challenges and solutions. Clin Interv Aging 2017;14;12: 1957-1965. (PMID: 29180859)

17. Nzerue CM, Baffoe-Bonnie H, You W, Falana B, Dai S. Predictors of outcome in hospitalized patients with severe hyponatremia. J Natl Med Assoc 2003; 95 (5): 335-43. (PMID: 12793790)

18. Krummel T, Prinz E, Metten MA, et al. Prognosis of patients with severe hyponatraemia is related not only to hyponatraemia but also to comorbidities and to medical management: results of an observation- al retrospective study. BMC Nephrol 2016;22; 17 (1): 159. (PMID: 27770791)

19. Castillo JJ, Vincent M, Justice E. Diagnosis and management of hyponatremia in cancer patients. Oncologist 2012;17 (6): 756-65. (PMID: 22618570)

20. Curtis JR. Palliative and end-of-life care for patients with severe COPD. Eur Respir J 2008; 32 (3): 796-803. (PMID: 17989116)

21. Skilbeck J, Mott L, Page H, Smith D, Hjelmeland-Ahmedzai S, Clark D. Palliative care in chronic obstructive airways disease: a needs assessment. Palliat Med 1998;12 (4): 245-54. (PMID: 9743823) 